\title{
SOME ADVANTAGES OF BUTT JOINTS OF THIN WROUGHT ALUMINIUM ALLOYS AMg5M AND AMg6M PRODUCED BY FSW, COMPARED TO TIG-WELDED JOINTS
}

\author{
A.G. POKLYATSKY, I.N. KLOCHKOV and S.I. MOTRUNICH \\ E.O. Paton Electric Welding Institute, NASU \\ 11 Bozhenko Str., 03680, Kiev, Ukraine. E-mail: office@paton.kiev.ua
}

\begin{abstract}
Comparative studies were performed of microstructure, degree of softening, ultimate strength, crack initiation and propagation susceptibility and fatigue resistance of welded joints of wrought aluminium alloys AMg5M andAMg6M $1.8 \mathrm{~mm}$ thick, produced by nonconsumable-electrode argon-arc welding and friction stir welding, as well as of the levels of residual longitudinal stresses developing in them. It is shown that application of FSW enables formation of permanent joint with minimum level of stress concentration in weld-to-base metal transition areas, and allows avoiding defects in the form of pores, oxide film macroinclusions and hot cracks in welds due to metal melting and solidification in fusion welding. Intensive plastic deformation of metal results in formation of a uniform disoriented structure under the tool shoulder and in the weld nugget with grain size of 3-4 $\mu \mathrm{m}$ and disperse (not more than $1 \mu \mathrm{m}$ ) phase precipitates, and grain elongation and distortion in the direction of plasticized metal displacement occur in the adjacent areas. This leads to increase of metal hardness in the joint zone, sample ultimate strength at uniaxial tension, their fatigue strength and lowering of crack initiation and propagation susceptibility. Lowering of temperature of welded edges heating leads to lowering of maximum level of residual longitudinal stresses in welded joints by $25 \%$, compared to TIG welding. 16 Ref., 8 Figures.
\end{abstract}

$\boldsymbol{K} \boldsymbol{e} \boldsymbol{y} \boldsymbol{w} \boldsymbol{O} \boldsymbol{r} \boldsymbol{d} \boldsymbol{s}:$ friction stir welding, aluminium alloys, hardness, microstructure, ultimate strength, fatigue

Semi-finished products in the form of sheets, plates, strips, extruded panels, shape sections, rods, forgings, stampings, etc. from strong and ductile wrought aluminium alloys AMg5 and $\mathrm{AMg} 6$ are widely used in fabrication of variouspurpose welded structures operating at temperatures from -190 up to $+70{ }^{\circ} \mathrm{C}[1]$. Permanent joints in most cases are produced by various methods of fusion welding, at which the weld forms as a result of melting of a certain volume of materials being joined and filler wire in a common weld pool and their subsequent solidification in shielding gas atmosphere. This leads to structural transformations in the weld metal and areas adjacent to it, as well as formation of defects in the form of pores, oxide film macroinclusions and hot cracks, resulting in lowering of welded joint physico-mechanical properties [2-4].

Metal melting in the zone of weld formation can be avoided and properties of semi-finished products used to produce weldments can be preserved to a maximum degree at application of solid-phase friction stir welding (FSW) [5, 6]. Aluminium alloy heating at friction in the welding zone just to its plastic state, intensive mixing,

(c) A.G. POKLYATSKY, I.N. KLOCHKOV and S.I. MOTRUNICH, 2015 deformation in a limited volume and its compaction by tool working surfaces result in formation of a finely-dispersed structure in the weld, and less softening of base metal (BM) in the HAZ than in fusion welding. This provides an increase of ultimate strength of such joints at uniaxial tension and their fatigue strength at cyclic loads, as well as lowering of residual stresses and deformations [7-14].

The objective of this work is determination of the advantages of butt joints of sheet wrought aluminium alloys AMg5M and AMg6M, produced by FSW, compared to those made by TIG welding.

Studies were performed on $1.8 \mathrm{~mm}$ sheets of aluminium alloys $\mathrm{AMg} 5 \mathrm{M}$ and $\mathrm{AMg} 6 \mathrm{M}$. Butt joints were produced by TIG welding at the speed of $20 \mathrm{~m} / \mathrm{h}$ at the current of 135-140 A with application of MW-450 system («Fronius», Austria), using $1.6 \mathrm{~mm}$ welding wires SvAMg5 and SvAMg6. FSW process was performed in laboratory unit developed at PWI with application of a special tool with a conical tip and shoulder of $12 \mathrm{~mm}$ diameter [15] with $1420 \mathrm{rpm}$ rotation speed and $12 \mathrm{~m} / \mathrm{h}$ linear displacement speed. The width of welds produced by nonconsumable electrode was $6.5 \mathrm{~mm}$ on average, and of those welded by FSW - $3.5 \mathrm{~mm}$ (at about $12 \mathrm{~mm}$ 
width of the thermomechanical impact zone (TMIZ) from the weld face side).

Sections were cut out of the produced welded joints to study their structure and samples with $15 \mathrm{~mm}$ gauge width were prepared to determine their ultimate strength at uniaxial tension to GOST 6996-66. Width of sample gauge part for fatigue resistance determination was equal to $25 \mathrm{~mm}$. Sample mechanical testing was performed in all-purpose servohydraulic system MTS 318.25. Cyclic testing was conducted under axial loads by sinusoidal cycle with coefficient $R_{\sigma}=0.1$ and $15 \mathrm{~Hz}$ frequency up to complete failure of samples. A series of 5-7 similar samples was tested under the same conditions. Experimental data of fatigue testing were processed by linear regression analysis methods generally accepted for investigations of this kind. Results of performed testing were used to plot for each sample series based on established limited fatigue limits the respective fatigue curve - regression line in coordinates of $2 \sigma_{\mathrm{a}}-\lg N\left(2 \sigma_{\mathrm{a}}\right.$ is the stress range, equal to doubled value of cycle stress amplitude).

Fracture resistance characteristics of BM and welds were determined on Kahn samples with a $\operatorname{sharp}(R=0.1 \mathrm{~mm})$ notch, providing crack initiation at relatively low energy level using an all-purpose RU-5 testing machine. The notch was located so that its tip coincided with weld axis. For each sample the ultimate strength and specific work of crack propagation at simultaneous bending and tension were determined, using load-deformation diagrams derived during their testing [16].

Metal hardness was measured on face side of scraped welded joints. Degree of metal softening in the joint zone was evaluated in ROCKWELL instrument at load $P=600 \mathrm{~N}$. Structural features of welded joints were assessed in optical electron microscope MIM-8.

Residual longitudinal stresses in welded joints were determined by experimental method based on metal cutting up. Relieved residual stresses due to welding heating were calculated by the magnitude of deformation of metal induced as a result of its cutting up, using the respective formulas of the theory of elasticity (Hooke's law).

Performed studies demonstrated that weld dimensions at FSW are smaller and its shape differs favourably from that of TIG weld (Figure 1). It does not have weld reinforcement formed in $\mathrm{fu}^{-}$ sion welding due to filler wire application or back bead due to application of a substrate with formed groove. This allows avoiding any significant stress concentration in areas of weld-to-base
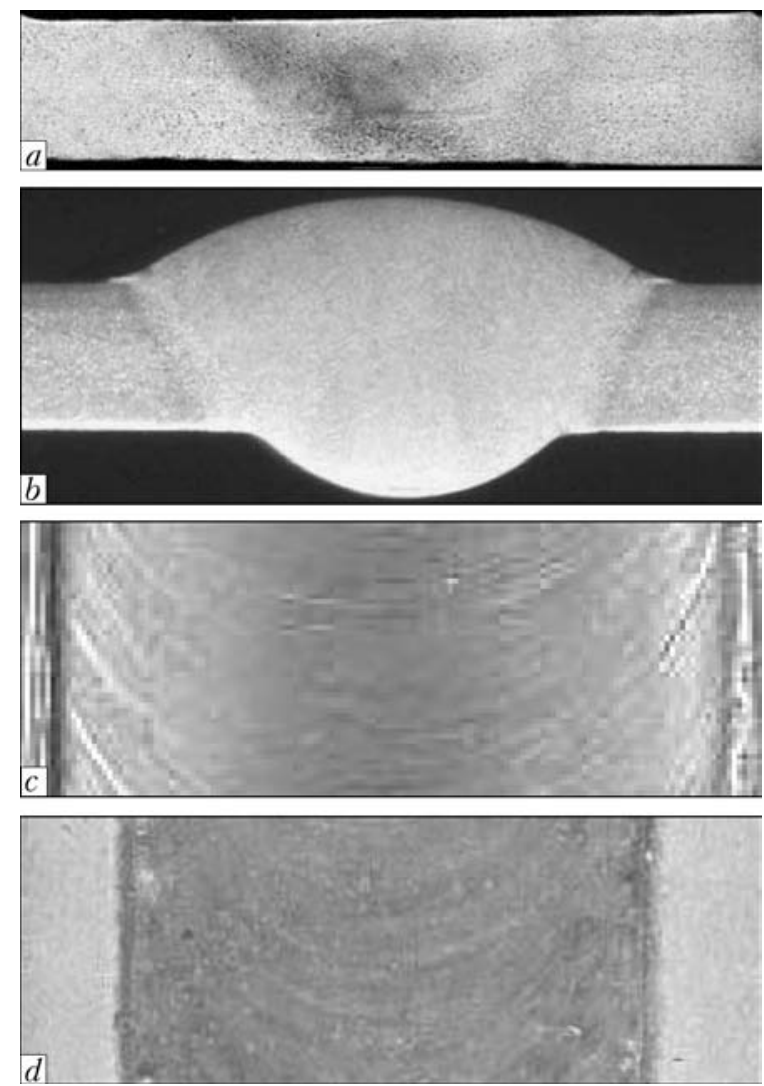

Figure 1. Cross-sections $(a, b)$ and appearance of weld face surface $(c, d)$ on $1.8 \mathrm{~mm}$ alloy AMg6M, produced by FSW $(a, c)$ and TIG welding $(b, d)$

metal transition, adversely affecting the operational and service life characteristics of the joints.

Moreover, formation of a permanent joint in the solid phase without melting of edges being welded allows avoiding their oxidation during welding. Intensive deformation and mixing of plasticized metal promotes mechanical softening and dispersion of initial oxide film on them, forming instantly on aluminium alloys. Therefore, FSW welds do not have any defects in the form of oxide film macroinclusions, quite often forming in TIG welding of aluminium-magnesium alloys (Figure 2). Absence of molten metal, in which hydrogen solubility rises abruptly, allows avoiding additional welding zone saturation by it due to this gas migration from adjacent surface layers of metal. Now, mixing and compacting of metal being welded in the joint zone ensures for-

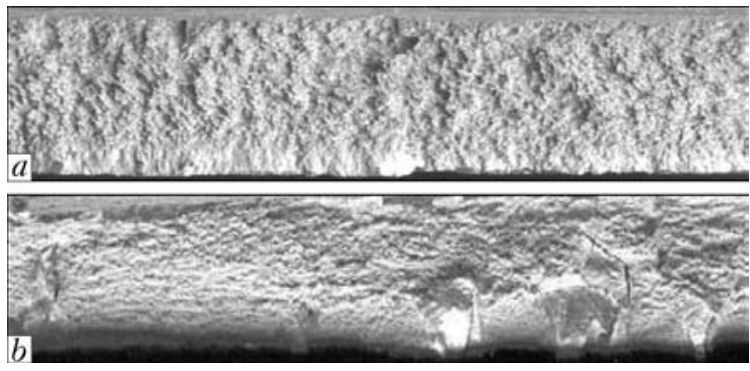

Figure 2. Longitudinal fractures of welds of $1.8 \mathrm{~mm}$ alloy AMg6M produced by FSW ( $a$ ) and TIG welding (b) 
SCIENTIFIC AND TECHNICAL

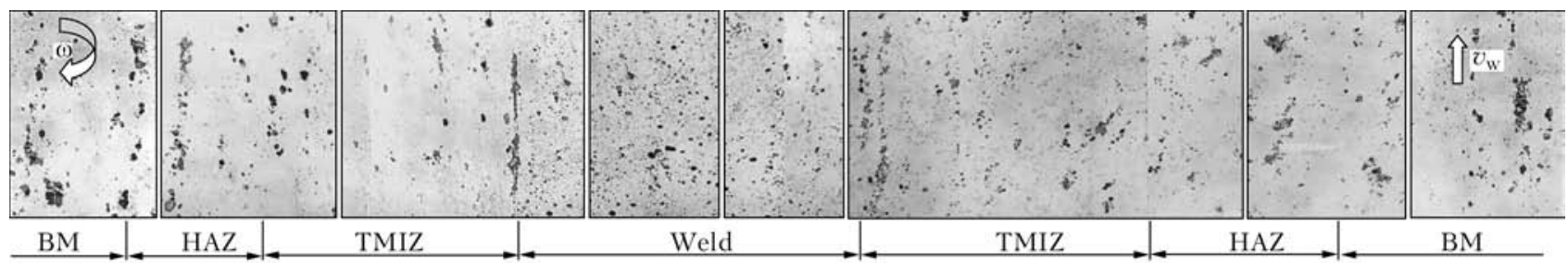

Figure 3. Microstructure $(\times 400)$ of surface areas of BM and FS-welded joint of AMg6M alloy, in the metal of HAZ, TMIZ and weld from the tool advancing (left) and retreating side (right)

mation of pore-free welds. As in FSW the processes of metal melting and solidification are absent, and the weld forms in the solid phase, it allows totally avoiding formation of the most dangerous and inadmissible defects in critical structures in the form of hot cracks appearing during solidification of molten metal in the sites of clusters of low-melting eutectic inclusions.

The process of permanent joint formation at FSW is a combination of a whole range of interconnected phenomena, including intensive local heat evolution on friction surfaces and cooling of small metal volumes in a closed space under high pressure, displacement of metal heated up to plastic state by a complex trajectory, plastic deformation in metal microvolumes, recrystallization, diffusion, mechanical crushing of component particles, intensive displacement of dislocations, instant formation of a permanent joint behind the tool, etc., that exactly determines the structural features of its various areas.

Microstructural studies showed that displacement of sufficiently thin $(0.1-0.2 \mathrm{~mm})$ layer of plasticized metal by tool shoulder surface, occurring during FSW, leads to an essential change of its structural condition - grain deformation, reorientation and refinement (Figure 3). Grains adjacent to metal being mixed are elongated and distorted in the direction of its mixing. From tool advancing side they are located practically parallel to the butt. Directly under the tool shoulder grain refinement occurs, but their clear orientation is absent.

Intensive displacement of plasticized metal by tool shoulder working surfaces across the entire thickness of edges being welded leads to formation of specific joint structure (Figure 4). In the weld central part (nugget) dynamic recrystallization results in formation of fine-crystalline weld metal structure. So, in weld nugget, the size of grains having a practically globular shape does not exceed $4 \mu \mathrm{m}$, and that of dispersed phase precipitates is not more than $1 \mu \mathrm{m}$, that is 5 to 7 times smaller than in BM. In TMIZ at the boundary of weld-to-base metal transition coarser grains $\left(6^{-7} \mu \mathrm{m}\right)$ are also found in addition to fine ones, the coarser grains being elongated in the direction of plasticized metal displacement. In HAZ metal, not subjected to deformational impact, grain size is equal to $10-15 \mu \mathrm{m}$.

TIG welds of these alloys are characterized by a mixed dendritic structure consisting of columnar and equiaxed grains typical for aluminiummagnesium alloys in as-cast condition. Equiaxed dendrites of about $25 \mu \mathrm{m}$ size form in weld central part. Near the zone of weld fusion with BM the laminated dendritic structure is more pronounced, with extended phase precipitates along these grain boundaries.

Intensive plastic deformation of metal in the zone of permanent joint formation in FSW not only promotes its structure refinement, but also leads to its deformational strengthening ( $\mathrm{Fi}^{-}$ gure 5). So, in the central part of welds of $\mathrm{AMg} 5 \mathrm{M}$ alloy metal hardness is on the level of $H R B 84$, and in the zones of its transition to $\mathrm{BM}$ it is equal to $H R B$ 83. Here, minimum hardness of metal ( $H R B$ 78) is observed in the HAZ, whereas at TIG welding in the weld central part metal hardness does not exceed $H R B$ 76, and in the zones of its fusion with BM - HRB 78 . Therefore, samples of joints of AMg5M alloy made by TIG welding with filler wire SvAMg5, with removed reinforcements and back beads fail through weld metal at uniaxial tension and have the ultimate strength on the level of $300 \mathrm{MPa}$. Samples of such joints with weld reinforcement fail through BM, similar to samples produced by FSW. Their ultimate strength is about $320 \mathrm{MPa}$.

Fracture of samples of AMg6M alloy welded joints produced by TIG method using filler wire Sv-AMg6 without weld reinforcements and back beads also runs through weld metal, and their ultimate strength does not exceed $325 \mathrm{MPa}$, while in similar sample with weld reinforcement, failing in the zone of weld fusion with $\mathrm{BM}$, this value is on the level of $345 \mathrm{MPa}$, similar to samples made by FSW, which fail through BM.

Load-deformation diagrams, derived at testing samples of BM and welded joints of $\mathrm{AMg} 6 \mathrm{M}$ alloy at their simultaneous bending and tension, are indicative of sufficiently high level of their ductility, as crack initiation at stress raiser tip occurs smoothly (Figure 6). Ultimate strength 

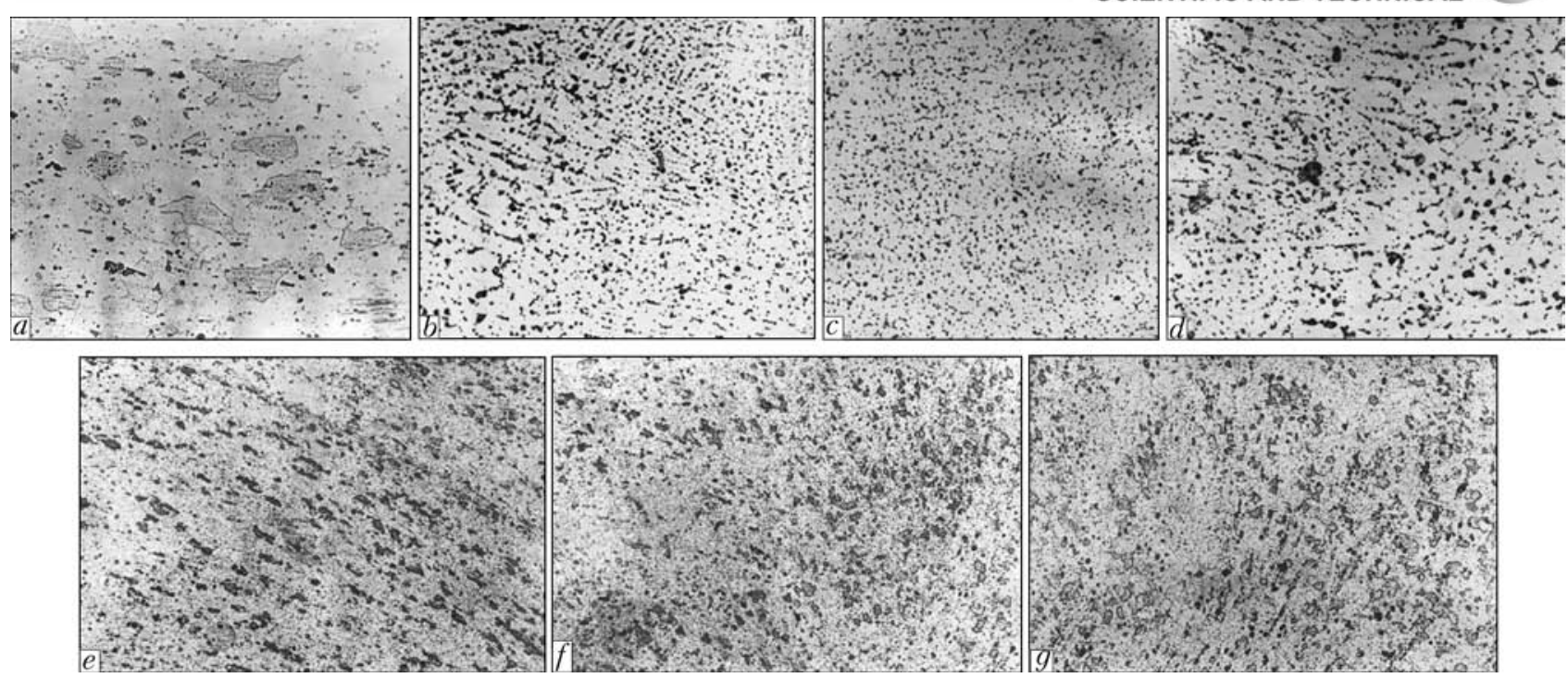

Figure 4. Microstructure $(\times 400)$ of BM $(a)$ and welded joints of AMg5M alloy produced by TIG method with filler wire SvAMg5 ( $b, d-$ zone of weld fusion with BM; $c-$ weld) and FSW ( $e-$ TMIZ from the advancing side; $f-$ weld nugget; $g-$ from retreating side)

of BM samples here is on the level of $415 \mathrm{MPa}$. Propagation of the crack initiating at sharp notch tip in TIG-welded samples occurs through weld metal. Ultimate strength of such a weld is lower compared to $\mathrm{BM}$, and is equal to $361 \mathrm{MPa}$. At testing of samples welded by FSW, the crack shifts to the zone of weld transition to BM, and their ultimate strength is on the level of $436 \mathrm{MPa}$. Crack propagation at testing of produced FSW samples also occurs slower than in BM. So, specific work of crack propagation in weld metal of such samples is on the level of $8.8 \mathrm{~J} / \mathrm{cm}^{2}$, whereas for BM of AMg6M alloy this value is equal to $5.7 \mathrm{~J} / \mathrm{cm}^{2}$, and for welds made by fusion welding it is $4.7 \mathrm{~J} / \mathrm{cm}^{2}$.

Fractographic analysis of fracture surfaces of FS-welded joint samples is indicative of ductile nature of weld fracture. Small pits with thin ridges are clearly visible in the weld central part at the tip of the raiser in the form of a sharp notch. Finely-dispersed weld structure provides a greater total length of grain boundaries that

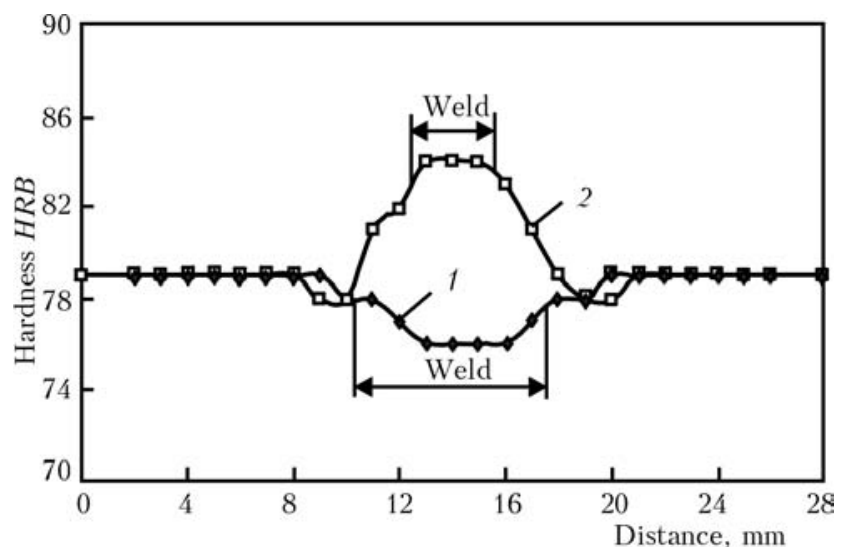

Figure 5. Hardness distribution in welded joints of $1.8 \mathrm{~mm}$ alloy AMg5M produced by TIG welding (1) and FSW (2) prevents an abrupt increase of stress concentration and hinders propagation of the main crack through weld metal. Therefore, increase of tensile load leads to the crack shifting into the zone of weld-to-BM transition, the fractograph of which reveals small flat areas of the relief, indicative

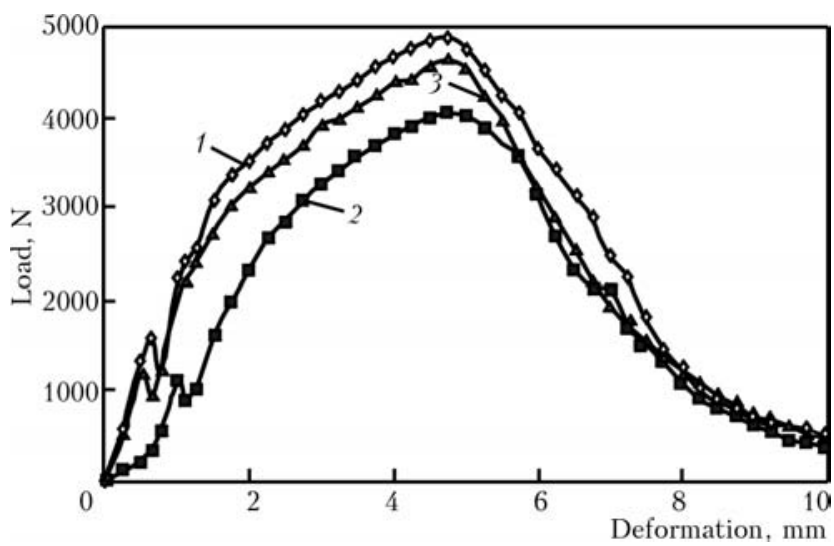

Figure 6. Load-deformation diagrams derived at testing samples of BM and welded joints of alloy AMg6M: 1 FSW; 2 - TIG welding; 3 - BM

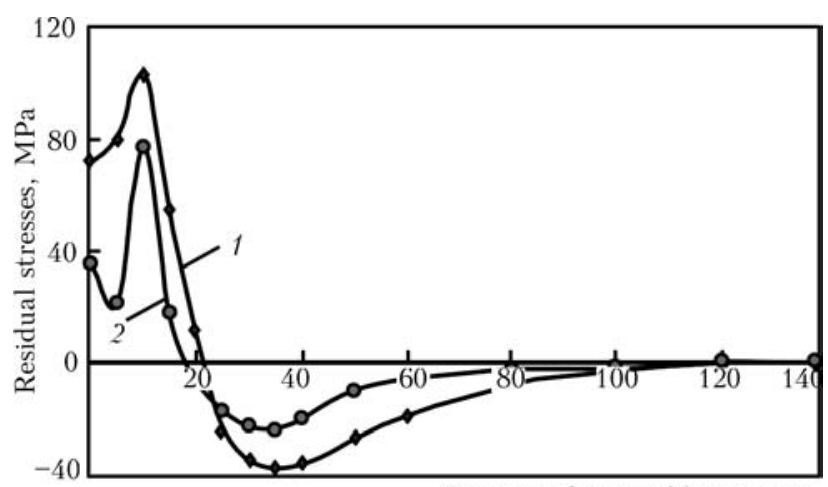

Distance from weld axis, $\mathrm{mm}$

Figure 7. Distribution of residual longitudinal stresses in welded joints of $1.8 \mathrm{~mm}$ alloy AMg6M produced by TIG welding (1) and FSW (2) 

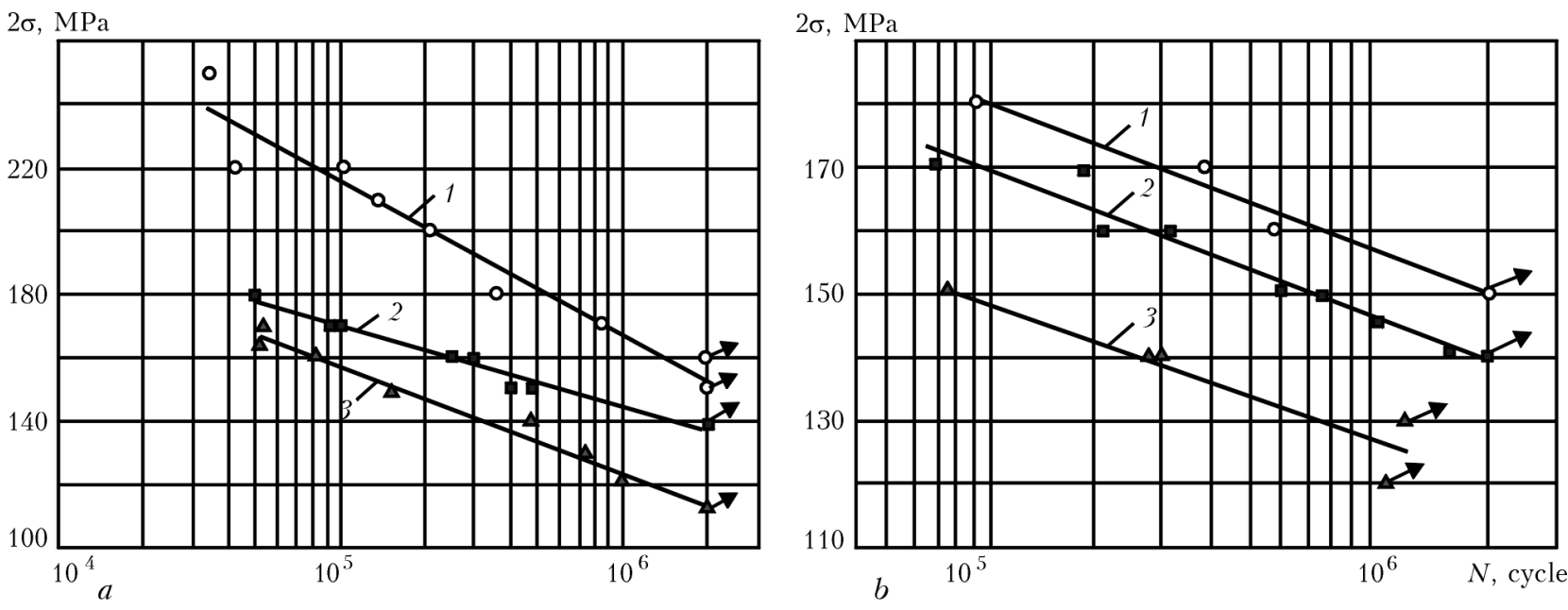

Figure 8. Fatigue curves of BM and welded joints of aluminium alloys $\operatorname{AMg} 6 \mathrm{M}(a)$ and $\operatorname{AMg} 5 \mathrm{M}(b) 1.8 \mathrm{~mm}$ thick at stress cycle asymmetry $R_{\sigma}=0.1$

of appearance of brittle fracture indications. However, prevalence of a homogeneous finelydispersed metal structure with uniform distribution of fine phase inclusions provides a higher level of metal strength even in this zone, compared to welds produced by fusion welding.

Performed research showed that lowering of metal heating temperature in the zone of permanent joint formation at FSW is favourable for the level of residual stresses resulting from nonuniform distribution of thermal field in it. So, at TIG welding maximum magnitude of residual longitudinal tensile stresses at $10 \mathrm{~mm}$ distance from weld axis is on the level of $103 \mathrm{MPa}$ ( Figure 7 ). In weld center these stresses are equal to $72 \mathrm{MPa}$. At about $22 \mathrm{~mm}$ distance from weld axis they drop to zero, which is followed by development of compressive stresses with maximum magnitude of $38 \mathrm{MPa}$ at $35 \mathrm{~mm}$ distance from weld axis. In welded joints made by FSW, maximum magnitude of tensile stresses is just $78 \mathrm{MPa}$. Here, their magnitude in weld center is on the level of $36 \mathrm{MPa}$ that is 2 times smaller than at TIG welding. Accordingly, maximum magnitude of residual compressive stresses at $35 \mathrm{~mm}$ distance from weld axis drops to $23 \mathrm{MPa}$.

Results of experimental studies of fatigue resistance of welded joints in aluminium alloys $\mathrm{AMg} 6 \mathrm{M}$ and $\mathrm{AMg} 5 \mathrm{M}$ produced in the solid phase by FSW demonstrated that their fatigue limit based on $2 \cdot 10^{6}$ stress cycles is equal to $85-95 \%$ of respective $\mathrm{BM}$ values, and practically reaches the level of the conditional fatigue limit values (Figure 8). In its turn, fatigue resistance of TIGwelded joints is markedly inferior in the entire fatigue life range based on $1 \cdot 10^{5}-2 \cdot 10^{6}$ stress cycles. Fatigue life of FSW joints is up to 10 times higher, compared to joints made by TIG welding, and their limited fatigue life based on $10^{6}$ stress cycles is higher by $15-20 \%$. The main cause for lower fatigue life of TIG-welded joints, chiefly, is the high concentration of acting stresses, due to weld geometrical features.

\section{Conclusions}

1. At FSW of aluminium alloys AMg5M and AMg6M intensive plastic deformation of metal under the tool shoulder and in weld nugget results in formation of a uniform disoriented structure with grain size of 3-4 $\mu \mathrm{m}$ and dispersed (not more than $1 \mu \mathrm{m}$ ) phase precipitates. In the zones of weld transition to BM elongation of some grains to $6-$ $7 \mu \mathrm{m}$ and their distortion in the direction of plasticized metal displacement take place.

2. FSW application ensures formation of permanent joint with minimum level of stress concentration in the areas of weld-to-base metal transition, and allows avoiding defects in welds in the form of pores, oxide film macroinclusions and hot cracks due to melting and solidification of metal in fusion welding.

3. At FSW of heat-hardenable alloys AMg5M and $\mathrm{AMg} 6 \mathrm{M}$, owing to strain hardening of metal due to its grain refinement, metal hardness in the joint zone becomes higher, whereas in fusion welding metal hardness in this zone decreases as a result of formation of cast coarse-grained dendritic weld structure. Therefore, ultimate strength of FSW samples at uniaxial tension is by $20 \mathrm{MPa}$ higher than that of samples without weld reinforcements and back beads, welded by TIG process. Fracture resistance values of samples at their simultaneous bending and tension are indicative of a higher resistance of joints, produced in the solid phase, to crack initiation and propagation.

4. Owing to weld formation in the solid phase at temperatures lower than those in fusion weld- 
ing, maximum level of tensile residual longitudinal stresses in welded joints of AMg5M alloy produced by FSW is by $25 \%$ lower than at TIG welding.

5. Effectiveness of FSW process application instead of TIG welding for fabrication of structures operating at alternating loads from aluminium alloys $\mathrm{AMg} 5 \mathrm{M}$ and $\mathrm{AMg} 6 \mathrm{M}$ has been substantiated experimentally by determination of fatigue resistance characteristics. It is shown that fatigue life of butt joints produced by FSW is much higher than that of joints made by TIG welding, and their limited fatigue life based on $2 \cdot 10^{6}$ stress cycles practically reaches the level of $\mathrm{BM}$ sample fatigue life, while being by 30 to $40 \%$ lower for TIG-welded joints.

1. Beletsky, V.M., Krivov, G.A. (2005) Aluminium al loys (composition, properties, technology, application): Refer. Book. Ed. by I.N. Fridlyander. Kiev: KOMINTEX.

2. Rabkin, D.M., Lozovskaya, A.V., Sklabinskaya, I.E. (1992) Metals science of welding of aluminium and its alloys. Kiev: Naukova Dumka.

3. Mashin, V.S., Poklyatsky, A.G., Fedorchuk, V.E. (2005) Mechanical properties of aluminium alloys in consumable and nonconsumable electrode arc welding. The Paton Welding J., 9, 39-45.

4. Poklyatsky, A.G. (2001) Peculiarities of formation of oxide film macroinclusions in weld metal of aluminium alloys (Review). Ibid., 3, 36-38.

5. Klimenko, Yu.V. Method of friction welding of metals. USSR author's cert. 195846. Int. Cl. B23K 35 /02. Fill. 09.11.1965. Publ. 04.05.1967.
6. Thomas, W.M., Nicholas, E.D., Needham, J.C. et al Friction stir butt welding. Int. pat. appl. PCT / GB 92 02203; GB pat. appl. 9125978.8. Publ. 1991.

7. Shibayanagi, T. (2007) Microstructural aspects in friction stir welding. J. Japan Inst. of Light Metals, 9, 416-423.

8. Pietras, A., Zadroga, L. (2003) Rozwoj metody zdrzewania tarciowego z mieszaniem materialu zgrzeiny (FSW) i mozliwosci jej zastosowania. Biul. Instytutu Spawalnictwa w Gliwicach, 5, 148-154.

9. Sato, Y. (2002) Relationship between mechanical properties and microstructure in friction stir welded Al alloys. J. JWS, 8, 33-36.

10. Larsson, H., Karlsson, L., Svensson, L. (2000) Friction stir welding of AA5083 and AA6082 aluminium alloys. Svetsaren, 2, 6-10.

11. Kluken, A., Ranes, M. (1995) Aluminium bridge constructions - Welding technology and fatigue properties. Ibid., 3, 13-15.

12. Ericsson, M., Sandstrom, R. (2003) Influence of melting speed on the fatigue of friction stir welds, and comparison with MIG and TIG. Int. J. Fatigue, 25, 1379-1387

13. Lanciotti, A., Vitali, F. (2003) Characterization of friction welded joints in aluminium alloy 6082-T6 plates. Welding Int., 8, 624-630.

14. Jata, K.V., Sankaran, K.K., Ruschau, J.J. (2000) Friction stir welding effects on microstructure and fatigue of aluminum alloy 7050-T7451. Metallurg. Transact. A, 31, 2181-2192.

15. Ishchenko, A.Ya., Poklyatsky, A.G. Tool for friction stir welding of aluminium alloys. Pat. 54096 Ukraine. Int. Cl. B23K 20/12. Fill. 30.04.2010. Publ. 25.10.2010.

16. Poklyatsky, A.G. (2011) Resistance of welds on thinsheet aluminium alloys to initiation and propagation of service cracks. The Paton Welding J., 10, 5-9.

Received 23.03.2015 